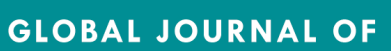 \\ Community Psychology Practice
}

\section{PROMOTING COMMUNITY PRACTICE FOR SOCIAL BENEFIT}

\section{Using Social Media as a Tool to Complement Advocacy Efforts}

\author{
J. Taylor Scott \\ University of North Carolina \\ at Charlotte
}

J'Vonnah Maryman

Wichita State University

Keywords: Advocacy; Communication; Empowerment; Social Media

Author Biographies: J. Taylor Scott is a Community Psychology doctoral student in the Health Psychology Program at the University of North Carolina at Charlotte. She consults on the communication strategies for the National Prevention Science Coalition to Improve Lives and is a member of the Society for Community Research and Action's Public Policy Committee. Her interests include child success and well-being, prevention of "rotten outcomes", and public policy and advocacy. J'Vonnah Maryman is a doctoral candidate in the Community Psychology Program at Wichita State University and holds a Masters of Public Health from the University of Kansas. She is a member of the Society for Community Research and Action's Public Policy Committee. Her interests include connecting public health and community psychology strategies to address health disparities, program planning, and public policy and advocacy.

Recommended Citation: Scott, J.T., Maryman, J. (2016). Using Social Media as a Tool to Complement Advocacy Efforts. Global Journal of Community Psychology Practice, 7(1S), pages 1-22. Retrieved Day/Month/Year, from (http://www.gjcpp.org/). 


\title{
Using Social Media as a Tool to Complement Advocacy Efforts
}

\begin{abstract}
Community practitioners must leverage a variety of tools in order to promote and advocate for social change. Social media are relatively innovative tools for informing and mobilizing communities in an advocacy effort. As part of a coordinated effort, social media align well with the principles of community psychology by enabling individuals to contribute to participatory dialogue about social issues, collaborate on change efforts, and establish a sense of community. These tools can enhance supporters' advocacy engagement and can help sustain efforts in the midst of inevitable challenges. However, social media alone are not sufficient for promoting social change, but should be used to enhance traditional organizing strategies. In addition to synthesizing literature across empirical and practitioner (e.g., communication consultants) sources, real-world examples are provided to illustrate how social media can enhance advocacy efforts. This article presents findings from an extensive literature review to serve as a resource for community practitioners on ways to enhance advocacy efforts with social media.
\end{abstract}

\section{Introduction}

Community psychologists engage in processes to transform and influence decisions within political, economic, and social systems. Traditional advocacy approaches include establishing relationships with legislators, creating and disseminating research syntheses (e.g., white papers), developing policy position statements or fact sheets, and sharing information through media outlets (e.g., opinion editorials, press releases; Maton, Humprheys, Jason, \& Shinn, in press). While these strategies have demonstrated effectiveness on local, state and national levels and in different policy domains, there is no true blueprint to moving social policy forward. Public policies continue to be influenced by multiple factors (Bogenschneider \& Corbett, 2010), which may vary depending on temporal context. For example, the widespread use of the internet has given rise to the "connected age," as society has increased reliance on social media to communicate and build relationships with one another (Fine, 2006). Community psychologists must adapt to the evolving communication patterns of society and adjust their strategies according to the communication needs of society. Agility and flexibility are essential because a stagnant organizing strategy will result in tepid support (Fine, 2006; Kanter \& Paine, 2012; Satariano \& Wong, 2012).

Broadly defined, social media are a set of interactive digital tools that connect groups of individuals interested in dialogue or information (Lovejoy \& Sexton, 2012). When used for advocacy, these tools help to build a network of supporters (see Fine, 2006; Lovejoy \& Saxton, 2012). Social media are also referred to as Web 2.0 because of their interactive capacity, and should not be mistaken for the World Wide Web, which does not enable interactions (Edwards \& Hoeffer, 2010). There are numerous social media tools, including blogs, videos, and social networks (Brunson \& Valentine, 2010; Edwards \& Hoeffer, 2010; Kanter \& Paine, 2012). Each tool has unique features that have the potential to expand the reach of information across individuals, organizations, and communities, as communications can spread quickly among a vast group of people (Bakshy, Rosenn, Marlow \& Adamic, 2012; Fine, 2006; Kanter \& Paine, 2012; Satariano \& Wong, 2012). Furthermore, social media expand the reach and inclusivity of an advocacy campaign by enabling supporters to 


\section{Global Journal of Community Psychology Practice}

join a cause regardless of geographic location, timing, or disability (Satariano \& Wong, 2012).

Although social media use has apparent benefits, many community practitioners are uneasy about how and when to leverage these tools in their work (Brunson \& Valentine, 2010). Community practitioners' abilities to integrate social media in social change efforts may relate to the sprawl of the literature base across disciplines and between empirical and practitioner (e.g., consultant) recommendations. In an effort to improve community psychologists' familiarity and comfort with social media, the following paper reviews diverse sources across disciplines to describe how social media can complement traditional advocacy and social change efforts. The present review informed the development of a conceptual framework to describe how advocacy-related goals and community psychology values can be supported by social media.

The paper integrates examples of social media use in social change movements, largely focusing on the United States (U.S.) because of the availability of research and practice recommendations generated in this country. It is important to note that policy processes and civic engagement norms vary tremendously among political climates (e.g., social media use is constrained by government laws in many Arab countries; Ghannam, 2011), which may have an impact on the effectiveness of social media and advocacy strategies. As such, an effort was made to include examples of work across international boundaries; however, much more empirical work is needed to understand how socio-cultural and political contexts may play a role in shaping the successful use of social media in social change efforts.

\section{Social Media and Advocacy}

Efforts that use social media in isolation are not likely to be successful; however, social media can augment organizers' existing strategies for communicating about public issues, building relationships and collaborations with supporters, and encouraging greater involvement among supporters (Fine, 2006; Kanter \& Fine, 2010). Moreover, social media may supplement a range of offline tactics (e.g., events or protests; face-to-face community building; Brunson \& Valentine, 2010; Satariano \& Wong, 2012). Offline strategies may be particularly important for engaging segments of the population who prefer traditional methods of communication (e.g. cell phone); however, traditional contact information (e.g., phone number, address) may be subject to change, and social media help overcome that challenge by increasing the number of available channels for communication (Thackeray \& Hunter, 2010).

Overall, offline and online approaches should be used in combination to enhance the effectiveness of a social change effort. Previous research has noted that the combined use of social media and traditional organizing approaches create a "hybridity between physical and virtual space" (Penney \& Dadas, 2014, p. 80). This was exemplified in the Occupy Wall Street (OWS) movement, which utilized Twitter, a micro-blogging social network site used for information sharing, to solicit donations for on-theground needs, extend the reach of information shared during meetings, and allow participation among those not able to attend events (Penney \& Dadas, 2014). The need to incorporate both online and offline approaches was also demonstrated in an international effort aiming to create social change around the global youth HIV/Aids epidemic (Vijaykumar et al., 2014). Similar to hybrid online/offline organizing, social media blurs boundaries with traditional media (e.g., newspapers) as it supplements conventional channels by widely disseminating traditional media and expanding information with comments and alternative perspectives (Liang et al., 2014; Penney \& Dadas, 2014).

When used to augment advocacy efforts, social media can bolster outreach efforts by 


\section{Global Journal of Community Psychology Practice}

spreading information about a cause, reinforcing relationships among supporters, promoting participatory dialogue between group leaders and supporters, and strengthening collective action through increased speed of collaborative communication. Moreover, these tools are highly cost-effective, allowing advocacy organizations to do more for less (Brunson \& Valentine, 2010; Orbar, Zube, \& Lampe, 2012). In the past, communication between constituents and politicians was limited to letters, phone calls, or face-to-face meetings. In the digital age, social media expand communication channels with public officials, many of whom maintain Facebook and Twitter accounts, by allowing constituents to send brief messages and share information about public concerns. Furthermore, research suggests that the widespread use of social media among U.S. citizens provides an outlet for civic engagement. For example, a study conducted by the Pew Institute found that $60 \%$ of Americans use social network sites, and $60 \%$ of those individuals (39\% of all American adults) report using social media to engage in at least one civic or political activity, such as following elected officials, joining political or social issue groups, encouraging others to take action, or posting content or opinions about socio-political issues (Rainie, Smith, Schlozman, Brady, \& Verba, 2012).

\section{Social Media Advocacy Framework}

While social media technologies have the potential to increase communication with advocates (Guo \& Saxton, 2013), effective social change efforts require considerable engagement and action among supporters (Fine, 2006). Engagement occurs incrementally, and social media offer a "foot in the door" by recruiting new supporters and providing opportunities to build relationships over time to gradually increase supporters' engagement (Fine, 2006). For example, supporters may become aware of a public issue via social media, but organizers must strive to convert this awareness into actions that support the cause. This incremental strategy aligns well with what Kanter and Paine (2012) characterize as a "ladder of engagement," which depicts engagement as a continuum ranging in type and intensity. Low-level engagement behaviors include "clicking" and sharing; moderate behaviors include participating in electronic calls to action (e.g., emailing a representative, signing a petition); and high-level engagement behaviors extend beyond the digital platform (e.g., volunteering, donations) and reflect the actions that social movements most strive to promote among their supporters. Social movement organizers must build relationships with supporters over time to increasingly foster individuals' contributions (Fine, 2006; Kanter \& Paine, 2012).

It is important to note that participation in an online advocacy network can expand and contract, and individuals vary in the degree to which they participate. The most passionate members carry a heavy burden of operational tasks, whereas less engaged members are critical for sharing information widely with their own social connections (Fine, 2006). Less engaged members are also essential for developing new advocates because these individuals are ripe for potential engagement in future efforts. Moreover, all levels of participation are essential (Kanter \& Paine, 2012). The degree to which organizers are able to incrementally move supporters from awareness to action may be affected by a number of factors, many of which are unknown because of a lack of research on implementing a quality social media campaign.

To help illustrate how social media can complement advocacy efforts and contribute to shifting policy priorities, Figure 1 was developed by the authors to highlight key points found in the existing, albeit limited, research on implementing quality social media campaigns. The framework was largely informed by empowerment and organizing theories (Kloos, Hill, Thomas, Wandersman, Elias, \& Dalton, 2012) and social media 
consultant publications (Fine, 2006; Kanter \& Paine, 2012). It asserts that social media campaigns must be implemented with quality to contribute to increasing critical awareness about an issue, building relationships with diverse supporters, and mobilizing them for meaningful action (e.g., advocacy), which ultimately is expected to contribute to shifting policy priorities.

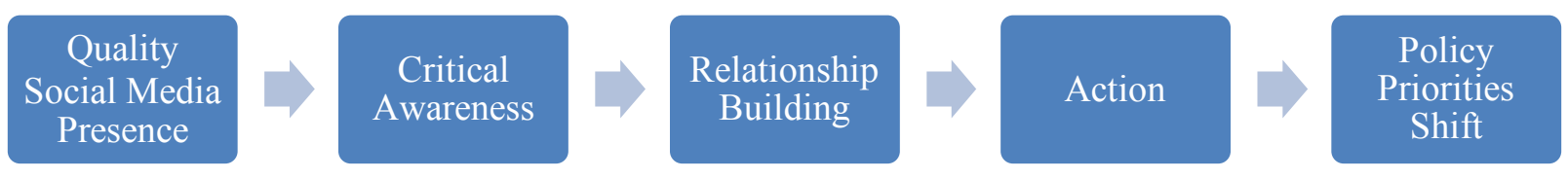

Figure 1: Social Media Theory of Advocacy and Policy Change

These objectives align with empowerment theory by emphasizing processes and interactions that elicit critical awareness, opportunities for meaningful participation, a place for supporters to engage with one another in solidarity, and settings that enable genuine inclusivity in collective action (Kloos et al., 2012). Information about the qualities that contribute to a successful social media campaign is provided throughout this paper, beginning with digital strategies to enhance critical awareness about a social issue, and ending with strategies to address common challenges to social media engagement.

It is important to note that while the conceptual framework presented in Figure 1 is intended to provide a schema describing mechanisms for shifting policy priorities, processes that shape policy are rarely as linear as a conceptual model might imply. Some social change organizations or groups may experience multiple iterations in processes, or observe reciprocal or reversal in the relationships among model components. For instance, multiple iterations and recursive cycles between critical awareness and relationship building may be required prior to engaging members in meaningful actions. Similarly, many cycles of meaningful action are likely required before social change efforts are anticipated to have meaningful impact on policy priorities.
The model is further limited by a lack of understanding about contextual influences (e.g., social issue, level of policy at which efforts target change, or cultural and political climate). In general, there is limited research to indicate under which circumstances specific strategies for social media advocacy may be most effective. Despite limited research, a few studies have highlighted the importance of context. For example, different social change efforts, Proposition 8 (i.e., concerning same-sex marriage in California) and OWS exhibited different predictors of success on YouTube. Scripted Proposition 8 videos were watched more often than live events or monologues; whereas, this trend was not apparent for OWS videos, which exhibited relatively equal distributions of engagement (i.e., views, ratings, comments) across video types (e.g., borrowed content, scripted versus live content; Vraga, Bode, Wells, Driscoll, \& Thorson, 2013). Another study examining participation in an international HIV social change effort identified contextual factors that influenced online and offline social movement participation, including internet access and usage, social stigma, and institutional trust (Vijaykumar et al., 2014).

Overall, the conceptual framework oversimplifies processes that shape policy priorities through social media advocacy because it does not account for contextual influences and proposes a logical order that 


\section{Global Journal of Community Psychology Practice}

may not hold true in all circumstances. Although flawed, the conceptual framework serves to organize key mechanisms found to contribute to social action and policy change. The sections that follow describe how processes pertaining to the framework are expected to mobilize a network of advocates, and additional limitations to the conceptual framework are further discussed.

\section{Critical Awareness}

Engaging supporters often begins with awareness and interest in a cause, and increasing interest drives the desire to actively contribute. For instance, joining a Facebook group or following a Twitter feed enables the individual to learn more information about the issue and increase their interest in supporting the cause (Kanter \& Paine, 2012). Furthermore, the interest of a few core supporters can enhance information dissemination when messages about the cause are shared beyond the reach of the organization and among personal social networks (e.g., friends, followers).

Information shared outside the organization's network increases the likelihood that new supporters find and join the cause (Satariano \& Wong, 2012). Additionally, messages that engage the audience in reflecting on the sociopolitical forces that underlie community issues can promote critical awareness, an attribute that may encourage citizen participation and empowerment (Kloos et al., 2012).

Supporters can engage in advocacy efforts in small but meaningful ways, including sharing messages through digital networks, which may be valuable for increasing public awareness and maintaining public attention to an issue (Brunson \& Valentine, 2010; Lovejoy \& Saxton, 2012). In fact, some activists involved in the OWS movement reported that sharing second-hand information on social media (e.g., re-tweeting on Twitter) was an important aspect of participation because these actions helped to recruit on-the-ground support and create an alternative information network, which was critical due to the selective coverage provided by mainstream media (Penney \& Dadas, 2014).

Although information dissemination is a critical component of an organized effort, this function alone does not promote action. Information dissemination involves one-way interactions that provide information, but often do not actively encourage supporters to contribute (Lovejoy \& Saxton, 2012). With that intent, it may be disappointing that information sharing is the primary purpose of nonprofit social media communications (Guidry, Waters, \& Saxton, 2014; Lovejoy \& Saxton, 2012). Nevertheless, informationsharing activities may inadvertently present opportunities for engaging supporters. For example, information sharing tweets may be more likely to be shared (i.e., retweeted) and generate conversations (i.e., two-way communications) than messages aimed at fundraising or event promotion (Guidry et al., 2014). Rather than focusing on engaging supporters in dialogue or action, information sharing has the potential to increase awareness about an issue, build support for a cause, and expand a digital network of supporters. For example, a 2010 targeted Twitter campaign has been credited in the efforts of Bahrain citizens who mobilized to push for the release of an internet blogger accused of conspiring against the country. The use of the Twitter social network to raise awareness of the blogger's arrest led to his release (Ghannam, 2011).

A network of supporters is an essential component of social media functionality, as it brings together individuals and organizations that may share information and collaborate in change efforts (Fine, 2006). The efficiency of networks is not a digital innovationnetworks have always been essential to social change (Kanter \& Paine, 2012). Ultimately, digital networks seek to recruit individuals who will engage at some level to support the cause. A trait that may be highly sought after is opinion leadership, the degree to which an 


\section{Global Journal of Community Psychology Practice}

individual enjoys promoting and discussing news and information among friends and followers (Park, 2013; Vraga, Anderson, Kotcher, \& Maibach, in press). These individuals reportedly use Twitter to express opinions, engage in political conversations, seek and share information, and aim to mobilize followers; therefore, these individuals may be critical to engaging individuals in public and political processes who are outside the reach of an organization's network (Park, 2013). Another study found similar patterns of engagement among Republicans seeking to lead opinions about climate change on Facebook. Opinion leaders tended to consume and post more information, and were more likely to rely on news sources than informal sources compared to non-opinion leaders (Vraga et al., in press). In short, engaging individuals who enjoy sharing opinions about news and information may increase the likelihood that messages reach individuals outside an organization's network.

Overall, a robust digital network efficiently increases the capacity for disseminating information (Fine, 2006), which has the potential to increase the number of "voices" communicating about specific issues (Guo \& Saxton, 2013). Issues and ideas have the potential for spreading very quickly through online social networks (Satariano \& Wong, 2012); therefore information (including multimedia) shared via digital networks contributes to the phenomenon of topics becoming "viral" or widely shared internet content. Information sharing can increase public awareness about an issue, and may reach outsiders who may choose to seek additional information by connecting or following the cause via social media. Consequently, a relationship with a new supporter is initiated, which can enhance the advocacy effort (Biddix, 2010).

\section{Relationship Building}

Widely recognized as valuable assets for shifting attitudes and behaviors (Guidry et al.,
2014), relationships contribute to advancing supporters' engagement, moving them from "passive bystanders to active supporters, to evangelists for their causes" (Kanter \& Paine, 2012, p. 174). Relationships can be enhanced by the interpersonal capacity of social media platforms, which enable genuine dialogue (i.e., two-way communication) that helps to develop mutual understanding and relationships between stakeholders (Guidry et al., 2014). Due to increasing recognition of the potential for social media to enhance relationships between government leaders and citizens, Arab leaders once hesitant about social media have begun using social media to engage in two-way communication with citizens by participating in question and answer sessions (Ghannam, 2011). In addition to conversational capacity, social media can promote collaboration among individuals across geographic distances and collective action by managing volunteers and calling supporters to action (Lovejoy \& Saxton, 2012). OWS activists used Twitter to connect with one another across the nation, which helped to develop relationships that were essential for communicating about processes, challenges, planning, and strategy development (Penney \& Dadas, 2014).

Aside from building relationships in digital space, social media also have the potential to bridge online and offline interactions.

Relationships are strengthened by in-person activities. Social media cannot completely replace the value of face-to-face-interactions; however, virtual spaces can augment relationships and enable supporters to participate in organizing processes quickly and inexpensively (Fine, 2006). Among OWS activists, the relationships established through Twitter were strengthened by faceto-face, on-the-ground interactions at events and meetings (Penney \& Dadas, 2014). The value of face-to-face interactions should not be discounted, thus highlighting the need for multifaceted approaches to relationship building. 


\section{Global Journal of Community Psychology Practice}

Corroborating that need are noteworthy limitations of social media for building relationships, as compared to face-to-face interactions that are known to help develop personal bonds and relationships (e.g., Brady, Young, \& McLeod, 2015; Christens \& Collura, 2012; Hara \& Huang, 2011). Online-only organizing efforts limit the degree to which some individuals can participate as some supporters may not want or know how to engage in digital spaces (Brady et al., 2015). Recognizing these limitations, in-person activities may best strengthen relationships with supporters and provide opportunities for involvement to those who are not digitally inclined. However social media plays a role by initiating relationships through information dissemination about the cause, bridges communication among constituents when face-to-face interactions are not possible, and encourages offline engagement by broadcasting involvement opportunities and events (e.g., Penney \& Dadas, 2014).

Digital relationships certainly do not substitute those built in-person, but augmenting those face-to-face meetings with emails, online discussion lists, conference calls, video conferences, or blogs will allow for a great deal of information to be shared and input to be gathered quickly and inexpensively (Fine, 2006). The next sections describe how social media advocacy efforts seeking to build relationships with supporters can be enriched using participatory approaches and by processes that encourage sense of community. These concepts align well with community psychology values and can be bolstered by social media (Brunson \& Valentine, 2010; Fine, 2006).

\section{Participatory Approaches}

Modern-day communications are often antithetical to participatory methods, which frequently resemble dictation or information sharing rather than discussion or conversation. These tendencies may be an artifact of the broadcast era during which organizations began to expect others to listen, but were not expected to listen in return (Fine, 2006). Consequently, society has become accustomed to one-way, unbalanced, inauthentic relationships. The status quo of communications has contributed to a "listening deficit" among organizations, resulting in little or no effort being taken among organizations to listen and understand their constituents. This can be a serious pitfall because listening, rather than pushing organizational message and strategies, aids in mobilizing supporters to action (Fine, 2006).

Organizations listen to constituents by inviting and reinforcing dialogue, and responding transparently, which signals that the organization cares about the constituent's perceptions and experiences. Organizations that listen are better able to identify the most salient issues for members of the community, which allows responsiveness to constituents by keeping a "finger on the pulse of the community" (Guo \& Saxton, 2013, p. 64). This information enables organizational strategic improvements, and the process of responding to supporters' questions, concerns, or suggestions has the potential to enhance supporters' satisfaction, trust, commitment, and engagement in the cause (Fine, 2006; Kanter \& Paine, 2012).

Social media strengthen the capacity for interactive, two-way conversations (Brunson \& Valentine, 2010; Guo \& Saxton, 2013; Fine, 2006; Lovejoy \& Saxton, 2012) that have the potential to reinforce the gradual increases in engagement that Kanter \& Paine (2012) suggest are necessary for promoting action among supporters. For example, Twitter messages that aim to directly communicate and build a sense of community among supporters tend to be most successful at generating conversations compared to those that merely disseminate information (Guidry et al., 2014). This suggests interactions using social media may promote a moderate level of engagement that is a critical antecedent to high-level engagement behaviors (e.g., 


\section{Global Journal of Community Psychology Practice}

volunteering, responding to calls to action; Kanter \& Paine, 2012).

Conversations can also be used to create meaningful opportunities for participation (e.g., involvement in deciding goals and activities), as opposed to impersonal invitations to join a campaign or give a donation. In this article, "meaningful participation" is defined as citizen involvement in decision-making and access to resources that inherently shift power from leaders to constituents (Kloos et al., 2012). Highly meaningful forms of participation include opportunities for members to contribute to the group's identity, goals, activities, or other decisions and are essential for enhancing buy-in and increasing enthusiasm to implement strategies to achieve group goals (Brunson \& Valentine, 2010; Fine, 2006). These engagement strategies align with participatory values in empowerment approaches by decentralizing decision-making and allowing greater participant control over processes that define the problem, solutions, and methods for achieving social change (Kloos et al., 2012).

Although some leaders may find it counterintuitive to relinquish some authority, decentralized organized networks tend to be most efficient and sustainable. In contrast to traditional top-down organizing methods, participatory engagement promotes voluntary action among supporters, which requires fewer resources to carry out social change strategies (Fine, 2006). While the leadership role remains highly important for promoting a common vision and mobilizing the network of supporters, it is expected that the benefits of participatory approaches far outweigh the costs. The more the network is engaged in meaningful participation, the stronger the network becomes (Fine, 2006). In general, decentralized networks are more adaptable and resilient to change because the organization does not become unstable if one or more leaders step down. Furthermore, individuals increasingly expect to be involved in decision-making processes because the internet has begun to decentralize power in all aspects of life (Beato, 2014), which makes decentralized advocacy efforts adaptive to the demands of modern society.

Decentralized, participatory governance structures can take several forms. As a case in point, an organization seeking to address street sexual harassment involved women in a participatory digital story telling process using an online forum (Dimond, Dye, LaRose, \& Bruckman, 2013). The process enabled participants to share sexual street harassment experiences, which in turn helped to redefine the problem as symptomatic of a greater social issue - the position of women in society. The process not only promoted critical awareness among participants, but also helped to fundamentally shift perspectives about the nature of the problem (Dimond et al., 2013). Women recognized that the status quo restricts women from recognizing the phenomena as problematic, pushing them to believe that sexual street harassment is something they "had to accept" and should "ignore it and walk quickly away" (p.6). When women recognized the collective problematic nature of sexual street harassment, they began to shift away from "victim blaming" to identify potential solutions and attempt actions (e.g., posting about issue on Facebook; confronting harassers). Some participants felt empowered in the process and sought to further their activism role (Dimond et al., 2013).

\section{Sense of Community}

Participatory strategies that empower supporters to make meaningful contributions to a cause (e.g., decision-making processes) can aid in the development of another community psychology value - sense of community, which is characterized by perceived similarity in identity, shared emotional experiences, and interdependence (e.g., fulfilling one another's needs; Sarason, 1974). For instance, participatory approaches that demonstrate an organization has listened to supporters' ideas and concerns promote 


\section{Global Journal of Community Psychology Practice}

trust and bonds among supporters (Fine, 2006). Additionally, virtual meeting spaces that invite members to discuss experiences help form interpersonal connections and generate shared emotional experiences (Kanter \& Paine, 2012), which was demonstrated by the participatory storytelling approach described by Dimond and colleagues (2013).

In addition to participatory approaches, digital settings can promote sense of community by explicating group values, norms, and visions. This explication, in turn can strengthen identification with the group by enhancing perceptions that members are tied by shared beliefs, which was demonstrated in a study among university students in eastern China (Zhou, 2011). Recognition of shared values and social support between members can bolster empowerment and engagement among group members by enhancing solidarity, promoting individual participation, and encouraging a sense of collective efficacy characterized by confidence in working together to effect change (Kloos et al., 2012). In the context of advocacy, group members are bound by shared values related to a social issue, which draws individuals to join a virtual group, but does not automatically engender a sense of community.

Social media can provide virtual homes where sense of community may develop (e.g., Lovejoy \& Saxton, 2012; Zhang, 2010), but a digital space is not sufficient for facilitating a sense of community and member commitment - organizations must actively support sense of community by providing opportunities for relationship development both online and offline (Fine, 2006). Organizations can create settings that promote solidarity by providing opportunities for meaningful interactions and participation (Kloos et al., 2012); however, interactions among members are critical for generating shared emotional experiences and developing sense of community (Fine, 2006). Therefore, organizations cannot "create" sense of community without supporters' participation because organizations cannot generate emotions (Fine, 2006). As one example of an online activist group that successfully promoted sense of community among supporters, MoveOn.org used social media to disseminate information, involve supporters in activities, and facilitate interaction. Continuous online communication among supporters eventually helped MoveOn to grow a sense of community (Hara \& Huang, 2011).

Facilitating interactions and continuous communication among supporters can be aided by digital information and communication technologies. These interactions help to develop sense of community over time by engaging members in meaningful interactions with one another and participation in decision making (Obar et al., 2012). These opportunities promote a collective identity, create bonds that mobilizing participants to engage in collective action, and generate commitment for sustaining those actions (Fine, 2006; Hara \& Huang, 2011; Koh, Kim, Butler, \& Bock, 2007). Additionally, OWS activists reported that informal interactions via Twitter promoted a sense of community and solidarity by creating bonds between activists, boosting morale, and bridging interactions with faceto-face events (Penney \& Dadas, 2014).

\section{Mobilizing Action}

Volunteering and other forms of high-level engagement are an ultimate goal of organizers so that supporters get involved and contribute to a cause (Fine, 2006).

However, some social science scholars are skeptical about the degree to which online communities can promote such meaningful contributions because social media activism may "cheapen" political engagement by engaging supporters in low-cost efforts, dispiriting the public when their efforts are ignored, or by crowding out higher levels engagement. This phenomenon has been termed "slactivism" (see Karpf, 2010). 


\section{Global Journal of Community Psychology Practice}

Concerns of slacktivism parallel those described by Robert Putnam (2000), who noted that declining trends in political participation (e.g., voting, engaging in political activities) were primarily attributable to generational differences and evolving technologies (i.e., television). The digital age may also contribute to evolving trends in civic engagement; however, there is little empirical support to suggest that the internet contributes to lower levels of political engagement. In fact, internet users tend to be more politically engaged than noninternet users. A meta-analysis has suggested that the internet may modestly support offline political participation, particularly when individuals consume online news or information about public affairs compared to merely discussing political views (Boulainne, 2009).

There are additional data to support a link between internet usage and increased civic engagement, such as the finding that Facebook users are more likely to vote than others (Hampton, Goulet, Rainie, \& Purcell, 2011). This trend may extend beyond voting behaviors, as a nationally representative survey revealed that $82-85 \%$ of social media users are active in some kind of voluntary group or organization, which is greater than the $75 \%$ national average. In general, those who use social media are more likely to join civic efforts compared to those who do not use the internet or social media (Rainie, Purcell, \& Smith, 2011). In whole, studies suggest that social media and internet use may contribute to meaningful forms of offline engagement; however, the research is limited by a lack of longitudinal designs. The primary use of cross-sectional data cannot be used to ascertain a temporal sequence to suggest social media usage may increase civic engagement (Boulainne, 2009).

Other studies connect social media or internet use directly with engagement in social change efforts and conclude that information communication technologies appear to provide opportunities for modern- day civic engagement. Facebook groups are one mechanism for disseminating information that engages individuals and promotes later action. For example, college students who participate in political discourse through Facebook groups tend to be more engaged in offline political actions (e.g., calling an elected official; Conroy, Feezell, \& Guerrero, 2012). In general, social media are becoming a popular feature of political engagement among Americans (Rainie et al., 2012). Additionally supporting the link between online information and offline action is a study that found online recruitment efforts were reportedly more successful than offline efforts for advancing organizational membership and attendance at offline political protests (Gervais, 2015).

Studies regarding OWS have reported similar findings about the potential benefit of social media to offline engagement. Those who participated in the OWS via Facebook or Twitter were more likely to participate in offline OWS events compared to a non-OWS control group, even after accounting for individual differences, such as willingness to get involved in politics. In essence, those who used social media for low to moderate online engagement in the cause were more likely to be highly-engaged through related offline activities (García Albacete, Theocharis, Lowe, \& vanDeth, 2013). Furthermore, some OWS activists have reported intentionally using Twitter as an "e-mobilization" tool to share information about offline protest opportunities and facilitate offline action. It is expected that the speed and widespread distribution of information via Twitter may have increased turnouts at OWS protests (Penny \& Dadas, 2014).

These studies highlight the potential for social media to encourage meaningful offline political engagement, but modest forms of online engagement should not be discounted. Action can be as simple as signing an epetition (Fine, 2006). E-petitions in particular have demonstrated that small, collective efforts of many individuals have the potential 


\section{Global Journal of Community Psychology Practice}

to create substantial impact. Petitions have been used for organizing social change efforts for centuries, but digital tools complement this traditional strategy by expanding the reach to additional supporters (Beato, 2014). Change.org (n.d.a), an e-petition giant, reported over 5,000 of their petitions in 2014 were victories (i.e., proposed action was accomplished). Signers are notified of these victories, which has the potential to transfer an individual's moment of attention into a sense of accomplishment (Beato, 2014). A particularly noteworthy example was the petition begun by the parents of Trayvon Martin, which promoted an international movement for racial justice and inspired millions to take action (Beato, 2014). The petition asked that charges be brought against the shooter; later on, a Florida State Attorney filed second degree murder charges (Change.org, n.d.b).

Despite the potential for social media to mobilize supporters, nonprofits may infrequently ask supporters to respond to calls to action. A study of a random selection of social work organizations engaged in advocacy found that non-profit social work organizations do not fully utilize social media. Only $8.1 \%$ of tweets sent out were intended to call followers to action, even though these types of messages were more likely than other types of tweets to be shared (i.e., retweeted) and engage supporters in dialogue with the organization (Guidry et al., 2014). If it is expected that online engagement is an important predecessor to offline engagement, advocacy groups must strategically engage supporters through effective messaging strategies, and increase the usage of calls to action as a resource for doing so.

\section{Challenges and Considerations}

As asserted in the overarching framework, implementing a quality social media campaign that successfully engages supporters requires substantial planning. Up to this point, the paper has described how social media may promote incremental increases in supporters' engagement, starting with disseminating information about issues, increasing critical awareness, and nurturing relationships among supporters and the organization. Successful social media campaigns manage these tasks in a way that propels supporters to become activists and substantially contribute to and sustain the effort. However, none of this can be achieved without recognizing the inherent challenges of establishing a quality social media presence.

The first step to establishing quality is allocating sufficient resources. While social media can reduce the cost of information dissemination and engage supporters (Hara \& Huang, 2011), developing a "free" account on Twitter or Facebook is no panacea. Quality campaigns require concerted time and thoughtful consideration. Organizations that successfully use social media typically spend about two and a half hours per week on Facebook alone (Satariano \& Wong, 2012). Dedicated time is important for being able to cultivate legitimate conversations (Guidry et al., 2014), yet organizations may lack the staff to focus on this effort. At minimum, organizations should designate a webmaster to monitor for spam and rude language to ensure that inappropriate posts are removed quickly (Brunson \& Valentine, 2010).

Resources are also needed for engaging an audience by maintaining a flow of posts (Brunson \& Valentine, 2010), subscriptions for services that collect important data to inform strategies, and for extending the reach of messages via paid content promotion. Promoted content, an explicit cost, can increase the dissemination of key messages, which may be critical for a campaign looking to gain visibility, support, and traction quickly (e.g., Beato, 2014). In short, social media may provide efficient means for accomplishing advocacy-related goals (Obar et al., 2012), but are not "free" because organizations and advocacy groups must dedicate substantive resources toward the development of an 


\section{Global Journal of Community Psychology Practice}

effective social media campaign (Satariano \& Wong, 2012).

Staff time is a salient need considering the struggle among many online groups to develop participation among a core base of members (Lampe et al., 2011). For example, the benchmark for moderate success is engaging approximately $2 \%$ of members in online participation (Brunson \& Valentine, 2010). This level of engagement may be due to a lack of personal connection, which can hinder virtual organizing (Obar et al., 2012); however, connections can be supported by staff capacity to respond to members and provide opportunities for interaction that promote sense of community (e.g., conversations about shared values), which may enhance digital participation (Fine, 2006; Zhang, 2010).

Challenges to establishing a strong quality social media presence extend beyond resources. Effective messaging strategies are also critical to addressing engagement challenges. Organizers should begin a strategic plan by determining which individuals are important stakeholders who can influence key decision makers, clearly defining a target audience (e.g., based on age, primary purpose of internet usage information or entertainment, the use of certain tools, frequency of social media use), and outlining measurable goals (Satariano \& Wong, 2012). Using age as an example characteristic for targeting an audience, literature suggests that older audiences are dutiful information receivers and tend to rely on credible sources of information that align with their social groups or parties (Wells, 2014). In contrast, younger audiences are less likely to engage in civic organizations, expect to participate in information sharing, and typically base involvement on personal interests rather than affiliations. Therefore, participatory approaches are particularly valuable for organizations seeking to build relationships with the next generation (Wells, 2014).
A well-defined target audience can also guide the use of certain social media platforms that range in capacities, including starting conversations (e.g., blogs, newsfeed, videos), building social networks (e.g., Facebook, Twitter), and collaborating (e.g., Wiki boards, Google docs; Kanter \& Fine, 2010). The chosen platform must be user-friendly for the target audience to create a virtual setting conducive to developing social bonds that allow members to fulfill one another's needs (Brunson \& Valentine, 2010; Zhang, 2010); therefore, understanding the technical capacity and communication patterns of the target audience may aid with the selection of a social media platform or range of platforms.

There are many other considerations regarding the use of specific social media platforms or tools that are beyond the scope of this article; however, the attached appendix (Appendix I) provides a brief overview of several popular tools to highlight strengths and weaknesses pertaining to advocacy efforts. In general, various social media tools offer different capacities that complement one another, which was demonstrated by organizers aiming to relocate the Society for Social Work Research (SSWR) conference in congruence with a local boycott regarding worker pay and working conditions (Brady et al., 2015). The effort leveraged a variety of digital tools, beginning with an e-petition that demonstrated support among 1,200 individuals in 15 countries, and recruited supporters in further digital communication. Organizers reported that different forms of social media were complementary such that YouTube videos were disseminated via Facebook, blogs described issues and featured personal stories, Twitter helped raise issue awareness and build community using a common hashtag, and Facebook enabled dialogue and mobilized advocates in disparate communities. The range of tools enabled communication among diverse supporters with varying technological capacities and helped to build trust and rapport among 


\section{Global Journal of Community Psychology Practice}

supporters over time. Organizers concluded that online efforts led to boots-on-the-ground organizing regarding SSWR policies intended to avoid similar situations in the future (Brady et al., 2015).

Although many examples highlight the potential for social media to engage and promote action among supporters, it is not always successful at doing so. Offline action requires effort, and sometimes discussions do not lead to action (Hara \& Huang, 2011). More research is needed to explicate under what conditions and which social media tools promote meaningful, offline action among supporters of a cause. For instance, there is much to learn about how social media platforms can successfully engage individuals in participatory approaches because so few individuals participate in online communication forums (Brunson \& Valentine, 2010). Moreover, it is unlikely that social media interactions will be as effective for promoting policy change as those occurring face-to-face (e.g., lobbying online versus inperson; Hara \& Huang, 2011). In general, social media may support a successful organizing effort, but may not by itself lead to sustainable, long-term changes. On-theground action is necessary (Brady et al, 2015).

It is also important to note that successful social media campaigns may be affected by qualities of implementation that are difficult to measure (e.g., effective messaging). Very little is known about the effectiveness of implementation strategies for facilitating participatory approaches, sense of community, or meaningful action, or about contexts in which certain strategies are most effective for moving supporters from passive followers to activists meaningfully engaged in online and offline action. Overarching suggestions from communication consultants include a number of generally effective messaging strategies, such as regularly posting positive, relevant, short and easy-toread messages; using personal stories over statistics; and providing links for more information (Kanter \& Paine, 2012; Kidwai \& Imperatore, 2011; Kanter, 2011).

Nevertheless, much more research is needed to understand the qualities of implementation that may be most successful for engaging supporters and promoting action.

\section{Limitations}

Though the work described in this paper highlights potential strategies for engaging audiences, much of the cited research in this paper has yet to be replicated, may not be generalizable, and most often does not support causality of relationships because of a tendency to rely on cross-sectional designs. The conceptual framework is limited by the lack of research regarding contextual factors contributing to the success of social media approaches. Furthermore, assumptions of the proposed, simplistic conceptual framework may be contradicted in some circumstances. For instance, assuming that information dissemination contributes to critical awareness and initiating relationships may counter instances where relationships are built prior to engaging an individual in an advocacy effort. In particular, strong relationships may enhance receptivity to critical messages regarding politically charged issues such as gun violence.

The conceptual framework also assumes that supporters will engage in participatory approaches if there are opportunities. However, participation is often limited in online efforts (Brunson \& Valentine, 2010) and these approaches may be most successful among younger audiences (Wells, 2014), whereas some audiences may be annoyed by interactive approaches. Additionally, this article describes sense of community as an asset for building an active network of supporters; however, sense of community may also reduce the likelihood of recruiting diverse supporters (Kloos et al., 2012), which may be exacerbated by self-selected involvement regarding social causes that align with an individual's narrow range of interests (Hara \& Huang, 2011). Additionally, 


\section{Global Journal of Community Psychology Practice}

sense of community can contribute to a "deadening conformity" (pp. 28; Kloos et al., 2012). In contrast to the framework's assumption that critical awareness and relationships are the necessary ingredients for successful engagement, conformity has the potential to promote or discourage meaningful action. At worst, norms of inaction may suppress meaningful action among individuals, even among those with whom organizers have built strong relationships.

\section{Future Directions}

Most work carried out by community psychologists, regardless of the extent of the research, consists of change efforts that are bolstered by data-informed quality improvement strategies. However, the need for evaluating social media advocacy efforts is heightened by the lack of empirical evidence that informs effective strategies or best practices. Consultants suggest that organizers should learn what is effective and appeals to the target audience by testing and evaluating strategies in action (Kanter \& Paine, 2012). This requires patience and willingness to experiment and adapt over time (Brunson \& Valentine, 2010). There is an overabundance of potential indicators that can be collected by an array of digital tools (e.g., Cyfe, Hootsuite), which necessitates the prioritization and specification of measurable goals to inform evaluation methods. Moreover, progress on goals must be reviewed frequently to inform improvements and efficient resource allocation. For a complete review of tools, metrics, and analytic approaches, including content analysis and social network analysis, see Kanter \& Paine (2012). In general, social media provides valuable feedback on communications that are not available through traditional media (e.g., newspapers do not measure "likes"), which enables organizations to modify and adapt strategies (Obar et al., 2012).

\section{Conclusion}

Although social media have become increasingly relevant to social change efforts, community practitioners' use of digital tools should be guided by concerted strategies and carried out using dedicated resources.

Strategic planning begins with goal definition, as groups should consider what they hope to accomplish long-term, identify steps to move toward the long-term goal, and then match appropriate tools to meet those goals (Satariano \& Wong, 2012). Community psychologists must recognize that social media cannot be used in isolation, but should augment traditional advocacy techniques to adapt to the demands of our evolving society. These tools align well with empowerment, participatory approaches, and sense of community, which are foundational values of community psychology practice (Kloos et al., 2012). Although challenges are to be expected, community psychology values and strategies for continuous quality improvement can guide the effective use of these tools to adapt to the latest social trends.

\section{References}

Bakshy, Rosenn, Marlow, \& Adamic (2012, April). The role of social networks in information diffusion. In Proceedings of the 21st International Conference on World Wide Web (pp. 519-528). ACM. doi: $10.1145 / 2187836.2187907$

Beato, G. (2014, Fall). From petitions to decisions. Stanford Social Innovation Review, 12, 21-27.

Biddix, J. P. (2010). Technology uses in campus activism from 2000 to 2008: Implications for civic learning. Journal of College Student Development, 51, 679-693. doi: 10.1353/csd.2010.0019

Bogenschneider, K., \& Corbett, T. (2010). Evidence-based policy making: Insights from policy-minded researchers and research-minded policymakers. New York: NY Routledge. 


\section{Global Journal of Community Psychology Practice}

Boulianne, S. (2009). Does internet use affect engagement? A Meta-Analysis of Research, Political Communication, 26, 193-211. doi: $10.1080 / 10584600902854363$

Bonetta, L. (2009). Should you be tweeting?. Cell, 139, 452-453. doi: 10.1 $016 /$ j.cell.2009.1 0.017

Brady, S. R., Young, J. A., \& McLeod, D. A. (2015). Utilizing digital advocacy in community organizing: Lessons learned from organizing in virtual spaces to promote worker rights and economic justice. Journal of Community Practice, 23, 255-273. doi: 10.1080/10705422.2015.1027803

Brunson, L., \& Valentine, D. (2010). Using online tools to connect, collaborate and practice. Global Journal of Community Psychology Practice, 1, 1-8.

Change.org (n.d.a). What you changed in 2014. Retrieved from https://www.change.org/year-inreview/2014

Change.org (n.d.b). Prosecute the killer of our son, 17-year-old Trayvon Martin. Retrieved from https://www.change.org/p/prosecut e-the-killer-of-our-son-17-year-oldtrayvon-martin

Christens, B. D., \& Collura, J. J. (2012). Local community organizers and activists encountering globalization: An exploratory study of their perceptions and adaptations. Journal of Social Issues, 68, 592-611. doi: 10.1111/j.1540-4560.2012.01765.x

Conroy, M., Feezell, J. T., \& Guerrero, M. (2012). Facebook and political engagement: A study of online political group membership and offline political engagement. Computers in Human Behavior, 28, 1535-1546.
Dimond, J. P., Dye, M., Larose, D., \& Bruckman, A. S. (2013, February). Hollaback!: The role of storytelling online in a social movement organization. In Proceedings of the 2013 conference on Computer supported cooperative work (pp. 477-490). ACM. doi:10.1145/2441776.2441831

Edwards, H. R., \& Hoeffer, R. (2010). Are social work advocacy groups using Web 2.0 effectively? Journal of Policy Practice, 9, 220-239.

Fine, A. (2006). Momentum: Igniting social change in the connected age. San Francisco, CA: John Wiley \& Sons.

García Albacete, G. M., Theocharis, Y., Lowe, W., \& Van Deth, J. W. (2013, March). Social media mobilisation as a prompt for offline participation? Analysing occupy wall street twitterers' offline engagement with the movement. Paper presented at 41st ECPR Joint Sessions of Workshops Johannes Gutenberg Universität, Mainz.

Gervais, E. A. (2015). Social network websites as information channels for the US social forum. Media, Culture \& Society, 37, 547-565. doi: $10.1177 / 0163443714566899$

Ghannam, J. (2011). Social Media in the Arab World: Leading up to the Uprisings of 2011. Center for international media assistance, 3. Retrieved from: http://www.databank.com.lb/docs/S ocial\%20Media\%20in\%20the\%20Ara b\%20World\%20Leading\%20up\%20t o\%20the $\% 20$ Uprisings $\% 20$ of $\% 2020$ 11.pdf

Guidry, J. P. D., Waters, R. D., \& Saxton, G. D. (2014). Moving social marketing beyond personal change to social change: Strategically using twitter to mobilize supporters into vocal advocates. Journal of Social Marketing, 4, 240-260. doi: 10.1108/JSOCM-02-2014-0014 


\section{Global Journal of Community Psychology Practice}

Guo, C., \& Saxton, G. D. (2013). Tweeting social change: How social media are changing nonprofit advocacy. Nonprofit and Voluntary Sector Quarterly, 43, 57-79. doi: $10.1177 / 0899764012471585$

Ghannam, J. (2011). Social media in the Arab world: Leading up to the uprisings of 2011. Washington, D.C.: Center for International Media Assistance. Retrieved from: http://www.databank.com.lb/docs/S ocial\%20Media\%20in\%20the\%20Ara b\%20World\%20Leading\%20up\%20t o\%20the $\% 20$ Uprisings $\% 20$ of $\% 2020$ 11.pdf

Hampton, K., Goulet, L. S., Rainie, L., \& Purcell, K. (2011). Social networking sites and our lives. Washington, D.C.: Pew Research Center's Internet \& American Life Project. Retrieved from http://www.academia.edu/download /30472786/Social_networking_sites_ and_our_lives_2011.pdf

Hara, N., \& Huang, B. Y. (2011). Online social movements. Annual review of information science and technology, 45, 489-522. doi: 10.1002/aris.2011.1440450117

Kanter, B. (2011, February). How to create and optimize a Facebook content strategy - Advice from Alison Zarrella. Retrieved from http://www.bethkanter.org/facebook -content/

Kanter, B., \& Fine, A. (2010). The networked nonprofit: Connecting with social media to drive change. San Francisco, CA: John Wiley \& Sons.

Kanter, B., \& Paine, K. D. (2012). Measuring the networked nonprofit: Using data to change the world. San Francisco, CA: John Wiley \& Sons.

Karpf, D. (2010). Online political mobilization from the advocacy group's perspective: Looking beyond clicktivism. Policy \& Internet, 2, 7-41. doi:10.2202/1944-2866.1098
Kloos, B., Hill, J., Thomas, E., Wandersman, A., \& Elias, M. (2012).Community psychology: Linking individuals and communities. Belmont, CA: Cengage Learning.

Kidwai, S., \& Imperatore, C. (2011). How to use social media as an advocacy tool. Techniques: Connecting Education and Careers, 86, 36-39.

Koh, J., Kim, Y. G., Butler, B., \& Bock, G. W. (2007). Encouraging participation in virtual communities. Communications of the ACM, 50(2), 68-73. doi: $10.1145 / 1216016.1216023$

Kristofferson, K., White, K., \& Peloza, J. (2014). The nature of slacktivism: How the social observability of an initial act of token support affects subsequent prosocial action. Journal of Consumer Research, 40(6), 11491166.

Lampe, C., LaRose, R., Steinfield, C., \& DeMaagd, K. (2011). Inherent barriers to the use of social media for public policy informatics. The Innovation Journal: The Public Sector Innovation Journal, 16(1), 1-17.

Liang, X., Su, L. Y. F., Yeo, S. K., Scheufele, D. A., Brossard, D., Xenos, M., ... \& Corley, E. A. (2014). Building buzz: (Scientists) communicating science in new media environments. Journalism \& Mass Communication Quarterly, 91, 772791. doi: $10.1177 / 1077699014550092$

Lovejoy, K., \& Saxton, G. D. (2012). Information, community, and action: how nonprofit organizations use social media. Journal of ComputerMediated Communication, 17, 337353. doi: 10.1111/j.10836101.2012.01576.x

Maton, K. I., Humprheys, K., Jason, L. A., \& Shinn, B. (in press). Community psychology in the policy arena. In M.A. Bond, C. Keys, \& I. Serrano-Garcia (Eds.). Handbook of Community Psychology. Washington D.C.: American Psychological Association. 


\section{Global Journal of Community Psychology Practice}

Mitchell, A., Kiley, J., Gottfried, J., \& Guskin, E. (2013). The role of news on Facebook. Pew Research Journalism Project. October, 24, 2013.

Obar, J. A., Zube, P., \& Lampe, C. (2012). Advocacy 2.0: An analysis of how advocacy groups in the United States perceive and use social media as tools for facilitating civic engagement and collective action. Journal of Information Policy, 2, 1-25. doi: 10.5325/jinfopoli.2.2012.0001

Park, C. S. (2013). Does Twitter motivate involvement in politics? Tweeting, opinion leadership, and political engagement. Computers in Human Behavior,29, 1641-1648.

Penney, J., \& Dadas, C. (2013). (Re)Tweeting in the service of protest: Digital composition and circulation in the Occupy Wall Street movement. New Media \& Society,16, 74-90. doi: 10.1177/1461444813479593

Putnam, R. D. (2000). Bowling alone: The collapse and revival of American democracy. New York, NY: Simon and Schuster.

Rainie, L., Purcell, K., \& Smith, A. (2011). The social side of the internet. Washington, D.C.: Pew Internet and American Life Project. Retrieved from http://www.itcnetwork.org/resource s/228-the-social-side-of-theinternet.pdf

Rainie, L., Smith, A., Schlozman, K. L., Brady, H., \& Verba, S. (2012). Social media and political engagement. Washington, D.C.: Pew Internet \& American Life Project. Retrieved from http://www.pewinternet.org/files/ol dmedia/Files/Reports/2012/PIP_Socia IMediaAndPoliticalEngagement_PDF.p df

Sarason, S. B. (1974). The psychological sense of community: Prospects for a community psychology. San Francisco: Jossey-Bass.
Satariano, N. B., \& Wong, A. (2012). Creating an online strategy to enhance effective community building and organizing. In Minkler (Ed.), Community Organizing and Community Building for Health and Welfare (pp. 269-287). New Brunswick, NJ: Rutgers University Press.

Thackeray, R., \& Hunter, M. (2010). Empowering youth: Use of technology in advocacy to affect social change. Journal of Computer-Mediated Communication, 15, 575-591. doi: 10.1111/j.1083-6101.2009.01503.x

Vijaykumar, S., Wray, R. J., Buskirk, T., Piplani, H., Banerjee, J., Furdyk, M., \& Pattni, R. (2014). Youth, New Media, and HIV/AIDS: Determinants of Participation in an Online Health Social Movement. Cyberpsychology, Behavior, and Social Networking, 17, 488-495. doi:

10.1089/cyber.2013.0124

Vraga, E. K., Anderson, A. A., Kotcher, J. E., \& Maibach, E. W. (in press). Issuespecific engagement: How Facebook contributes to opinion leadership and efficacy on energy and climate issues. Journal of Information Technology \& Politics. Advance online publication. doi: $10.1177 / 1461444813487962$

Vraga, E. K., Bode, L., Wells, C., Driscoll, K., \& Thorson, K. (2013). The rules of engagement: Comparing two social protest movements on YouTube. Cyberpsychology, Behavior, and Social Networking, 17, 133-140. doi:10.1089/cyber.2013.0117

Wells, C. (2014). Two eras of civic information and the evolving relationship between civil society organizations and young citizens. New Media \& Society, 16, 615-636. doi: $10.1177 / 1461444813487962$ 
Zhang, Z. (2010). Feeling the sense of community in social networking usage. Engineering management, IEEE transactions on, 57, 225-239. doi: 10.1109/TEM.2009.2023455
Zhou, T. (2011). Understanding online community user participation: a social influence perspective. Internet Research, 21, 67-81. doi: $10.1108 / 10662241111104884$ 


\section{Global Journal of Community Psychology Practice}

Volume 7, Issue 1S

February 2016

\section{Appendix I}

The following paragraphs review relative strengths and weaknesses of several popular social media platforms and tools.

\section{Twitter}

\section{Strengths}

- Rapid information exchange via condensed messages that provide concise headlines and additional information via links (Bonetta, 2009; Penny \& Dadas, 2014).

- A great resource for information exchange among scientists and the public (Bonetta, 2009; Liang et al., 2014).

- Recruiting a relatively specific population of working professionals (Satariano \& Wong, 2012).

- Few barriers to access, as anyone can access posts, even without an account or approved connections between accounts (Penney \& Dadas, 2014).

\section{$\underline{\text { Weaknesses }}$}

- Messages may be monitored by antagonists to the cause (e.g., OWS; Penney \& Dadas, 2014).

- Brevity limits the ability to promote meaningful dialogue (Bonetta, 2009; Penney \& Dadas, 2014).

- Presents technological barriers that may intimidate newcomers (Brady et al., 2015).

- It is uncertain whether or not Twitter promotes substantive engagement; only a small percentage of users have been found to take meaningful action (Satariano \& Wong, 2012). 


\section{Global Journal of Community Psychology Practice}

Volume 7 , Issue $1 \mathrm{~S}$

February 2016

\section{Facebook}

\section{Strengths}

- Provides a colossal social network (64\% of U.S. adults use it); offers a large, diverse audience across a range of ages (Brady et al., 2015; Mitchell, Kiley, Gottfried, \& Guskin, 2013).

- It can be used to expand the reach of inperson relationships (Biddix, 2010) and to share news and information (Mitchell et al., 2013).

- Accommodates social interest groups by providing virtual group spaces, which aid the development of a sense of community (Kanter \& Paine, 2012). Facebook groups can serve multiple purposes:

- Enhance meaningful actions among existing supporters through private groups; in contrast, public groups may enable token support via affiliation and public endorsements, which reduces the likelihood of engaging in meaningful supportive actions (Kristofferson, White, \& Peloza., 2014).

- Enhance critical awareness and outreach to prospective supporters through public groups that broadcast appealing and shareable content that reaches individuals outside the organization's network (Vraga et al., in press).

- Discussions essential to participatory approaches (Brunson \& Valentine, 2010) are more easily facilitated than on Twitter because there is no character limit.

\section{Weaknesses}

- Younger people often prefer other social media platforms (Brady et al., 2015).

- Most newsworthy content consumed on Facebook pertains to entertainment and sports (Mitchell et al., 2013), which suggests that the virtual setting is infrequently used for information exchange about social issues, and is more often used for information individuals find personally interesting or entertaining.

- Messaging strategies are particularly important because Facebook uses complex algorithms based on individuals' interests, behaviors, and interactions (e.g., "likes") that influence what information is available (Facebook, n.d.). In other words, if posts are not clicked, liked, or shared, fewer Facebook users will view the post. 


\section{Global Journal of Community Psychology Practice}

Volume 7 , Issue 1S

February 2016

Videos

Strengths

- Visual media can deliver powerful messages and is more accessible than written dialogues for some individuals, particularly those with intellectual disabilities (Brady et al., 2015).

- Can be used to illustrate a nonprofit's work or share information about specific issues, which is sometimes carried out by interviewing key informants or experts (Brady et al., 2105; Vraga et al., 2013; Satariano \& Wong, 2012).

- There are noteworthy uses of video for enhancing critical awareness in social movements (e.g., OWS and Proposition 8; Vraga et al., 2103).

\section{E-Petitions}

\section{Strengths}

- Enhance democratic values by creating an "incredible megaphone for everyday people" (pp. 21) and empower users with opportunities to create and promote content of concern to community members (Beato, 2014).

- Seek to enhance critical awareness about a cause within a specific platform's network and outside the network by reaching potential supporters via other communication channels (e.g., Facebook, email).

- Capacity to collect information about supporters, an initial step to forming a network (Beato, 2010).

- Capacities mirror the "foot in the door" approach for incrementally engaging supporters described previously (Fine, 2006) by introducing an issue, attempting to build awareness, and recruiting supporters for future engagement.

\section{$\underline{\text { Weaknesses }}$}

- Although sites like YouTube create their own social networks, video dissemination is enhanced by robust information sharing networks such as Twitter and Facebook.

- Limited technical capacity reduces ability to leverage videos frequently and effectively. Videos require cameras, editing software, and significant time for editing video footage (Brady et al., 2015).

- Public perception of accuracy and credibility of videos broadly (Brady et al., 2015), which may hinder perceived credibility of video efforts intending to disseminate information.

\section{Weaknesses}

- Ability to build relationships with supporters via digital communities, as the e-petitions enable endorsements but provide fewer opportunities for conversations through groups than social networks such as Facebook or Twitter.

- Ability to mobilize action among supporters, as the primary function is to demonstrate support for specific social change actions. 